\title{
Atrioventricular Septal Defect with Intact Interatrial Septum. Case Report
}

\author{
Papa Salmane Ba*, Yacouba Tamboura, Momar Sokhna Diop, Papa Amath Diagne, \\ Ndeye Fatou Sow, Papa Adama Dieng, Amadou Gabriel Ciss
}

Thoracic and Cardiovascular Surgery Departement, CHU Fann, Dakar, Senegal

Email: *mansalb@yahoo.fr

How to cite this paper: Ba, P.S., Tamboura, Y., Diop, M.S., Diagne, P.A., Sow, N.F., Dieng, P.A. and Ciss, A.G. (2020) Atrioventricular Septal Defect with Intact Interatrial Septum. Case Report. World Journal of Cardiovascular Surgery, 10, 143-149. https://doi.org/10.4236/wjcs.2020.108017

Received: June 11, 2020

Accepted: August 9, 2020

Published: August 12, 2020

Copyright $\odot 2020$ by author(s) and Scientific Research Publishing Inc. This work is licensed under the Creative Commons Attribution International License (CC BY 4.0).

http://creativecommons.org/licenses/by/4.0/

\begin{abstract}
In atrioventricular septal defect (AVSD), anatomical lesions usually are an ostium primum atrio-septal defect; a common atrioventricular valve, an inlet ventricular septal defect (VSD). It is most often associated with major chromosomal abnormalities. It is the most common congenital disease in Down syndrome. Our case was an infant with a Down syndrome who was admitted for a dyspnea (stage 3 in New York Heart Association classification) and tachycardia. The diagnosis was made by a transthoracic echocardiography. It showed a rare variety of atrioventricular septal defect without an atrial septal defect. The child was treated successfully with one patch technic and no recurrence was noted.
\end{abstract}

\section{Keywords}

AVSD, VSD, Dyspnea, Transthoracic Echocardiography, Patch

\section{Introduction}

Atrioventricular septal defect is a rare congenital heart disease [1]. It is common in major chromosomal abnormalities and Down syndrome is predominant [2]. The main lesion is a common atrioventricular junction and its variants depend on the attachment of the bridging leaflets at the atrial or the ventricular component of the septum [3]. It is classified into three anatomical forms that will determine the main clinical manifestations [3] [4]. Shunting in the atrial level is usually described in complete or partial atrioventricular septal defect; sometimes it can be absent because of the presence of an intact interatrial septum which can be explained by the attachment of the bridging leaflets to the interatrial septum [5]. In this paper we describe an atrioventricular septal defect with an intact septal component (no shunting in the atrial level) in a 20-month-old infant with 
Down syndrome to emphasize the variability of the so-called atrioventricular septal defect.

\section{Case Presentation}

This is a 20-month-old female infant without a history of disease or defects in her family. She was admitted to our department for a stage 3 dyspnea related to the New York Heart Association classification and a tachycardia. Symptoms evolved since seven (07) days of life. Physical examination found a Down syndrome morphology. The blood pressure was $102 / 70 \mathrm{~mm} \mathrm{Hg}$; heart rate was 119 beats per minute and the temperature was $36.7^{\circ} \mathrm{C}$. She was $7.2 \mathrm{~kg}$ weight and 72 $\mathrm{cm}$ height. A mesocardiac holosystolic murmur was also noted. No sign of heart congestion was noted. Chest $\mathrm{x}$-rays (Figure 1) showed cardiomegaly (cardiothoracic index: 0.70); a bulging left middle arc, a double-contoured appearance of the lower right arc, and pulmonary hypervascularization.

The electrocardiogram (EKG) found a regular sinus rhythm (136 beats per minute), right atrial hypertrophy (RAH), and right ventricular hypertrophy (RVH) (Figure 2).

A transthoracic Doppler echocardiography (TTE) showed the measurements as follows: $72 \%$ for left ventricular ejection fraction, $17 \mathrm{~mm}$ (Z: 0.83 ) for the diameter of the left ventricle (LV), $6.3 \mathrm{~mm}$ for the diastole interventricular septum, $22 \mathrm{~mm}(\mathrm{Z}:-2.74)$ for the diameter of the left atrium (LA), $8.7 \mathrm{~mm}(\mathrm{Z}:-1.47)$ for the right ventricle (Figure 3 ).

Another finding was the presence of a persistent left upper vena cava going into the coronary sinus, a $17 \mathrm{~mm}$ wide inlet ventricular septal defect (VSD) partially filled with tricuspid tissue but without straddling, a $50 \mathrm{~mm} \mathrm{Hg}$ transventricular gradient, moderate hypertrophy of pulmonary infundibulum with a maximum pulmonary gradient at $14 \mathrm{~mm} \mathrm{Hg}$; a no leaking cleft in left valve, and 2 normally disposed papillary muscles.

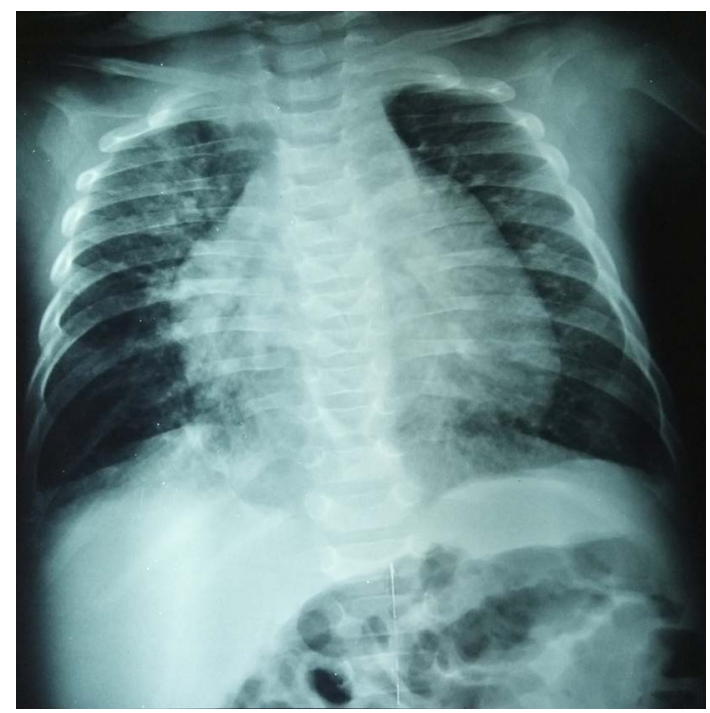

Figure 1. cardiomegaly and pulmonary hypervascularization. 


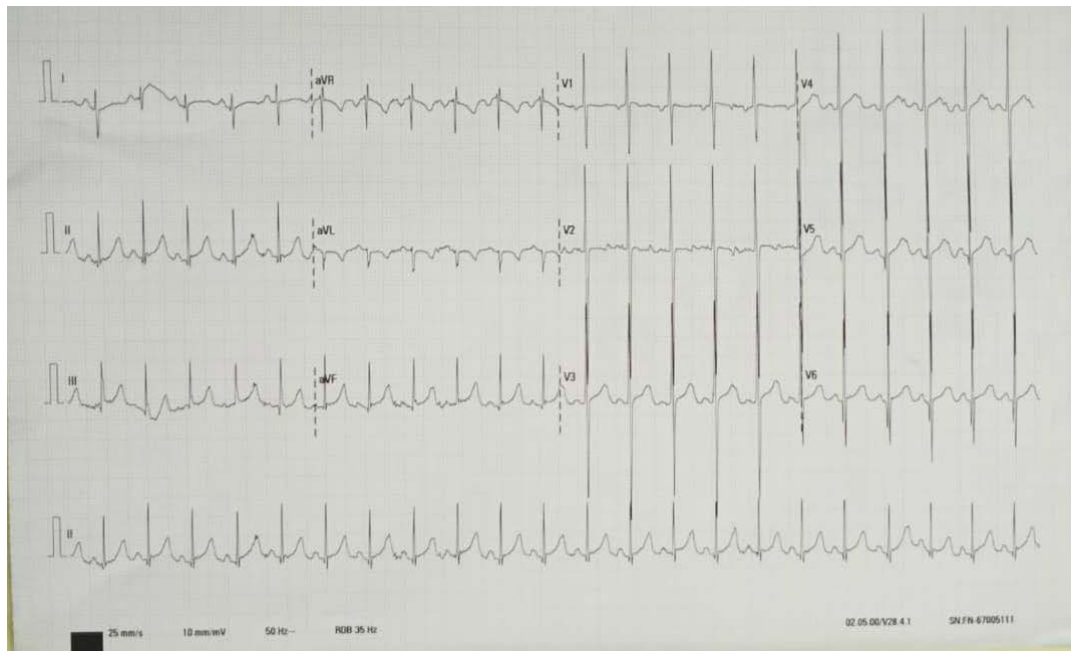

Figure 2. Sinus rhythm at 136 beats per minute, right atrial hypertrophy (RAH), and right ventricular hypertrophy $(\mathrm{RVH})$ in the electrocardiogram.

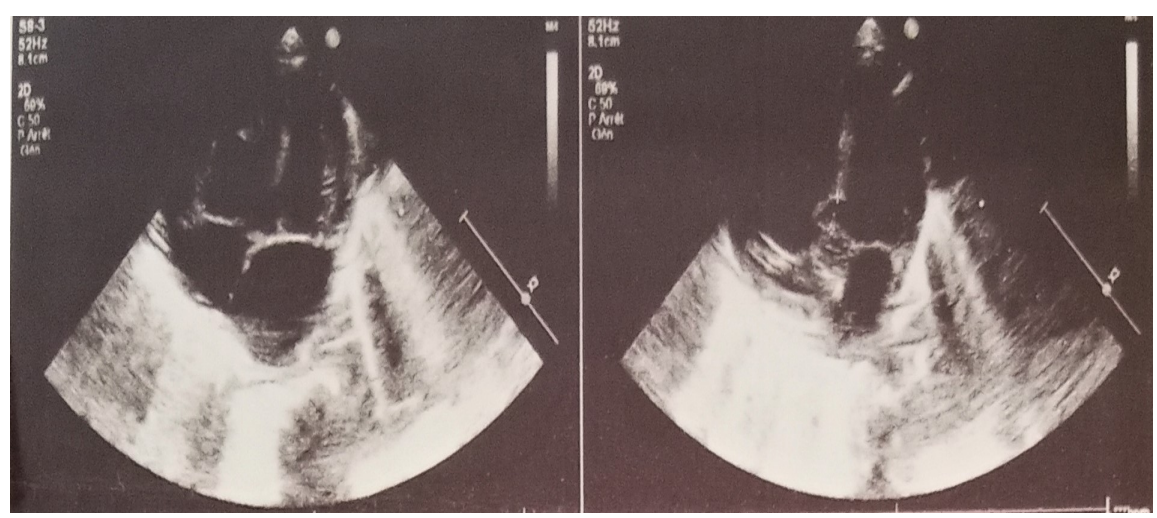

Figure 3. Precordial four chamber cut from a case with an atrioventricular septal defect and intact interatrial septum. The atrioventricular valves are at the same level and roof a defect in the inlet septum.

The biventricular function was good. There was an absence of atrial septal defect and aortic coarctation. The Ductus arteriosus was closed.

Cardiac catheterization had objectified pulmonary arterial hypertension (PAH) with a mean pulmonary arterial pressure (MPAP) at $72 \mathrm{~mm} \mathrm{Hg}$, a pulmonary hyperflow with Qp/Qs 3.3 and low pulmonary vascular resistances (VPR) with PVRI/SVRI 0.24 .

The patient received surgical management after medication (furosemide, spironolactone, and captopril). Surgical repair was performed via a median sternotomy. The child was operated under cardiopulmonary bypass with aorto-bicaval cannulation, and a modified Del Nido cardioplegia in moderate hypothermia $\left(34^{\circ} \mathrm{C}\right)$.

A large $17 \mathrm{~mm}$ inlet VSD, a single atrioventricular valve (AVV) with some attachment of the right component valve to the crest of the ventricular septum were founded. The left component (seen after opening the interatrial septum by the foramen ovale) had 3 leaflets with a "cleft" (no connection tongue between 
the superior and inferior bridging leaflets) at the anterior part; the right component had 3 leaflets. The left vena cava was drained with a venous cannula put in the dilated coronary sinus. The diagnosis was an atrioventricular septal defect with an intact interatrial septum.

The VSD was closed by a heterologous pericardial patch with $6 / 0$ polypropylene. The "clef" was closed. A plication calibrated to its right Hegar dilatator of the left component ring was made for annuloplasty. Then the interatrial septum was closed without a patch.

At the intensive care units, the child had a junctional tachycardia which evolved well under hydrocortisone (Figure 4), a bronchopulmonary infection that required oxygen treatment and antibiotic therapy; a residual pericardial effusion that regressed under enhanced diuretic treatment and ibuprofen. The patient was discharged after 6 days in the intensive care unit and 18 days after surgery. The Doppler echocardiography at 6-month after correction objectified a patch in place with a $2 \mathrm{~mm}$ leak, a mild mitral valve leak, and a good function of ventricles (LVEF: 65.5\%), TAPSE at $12 \mathrm{~mm}$; systolic pulmonary arterial pressure (SPAP) at $38 \mathrm{~mm} \mathrm{Hg}$ (Figure 5).

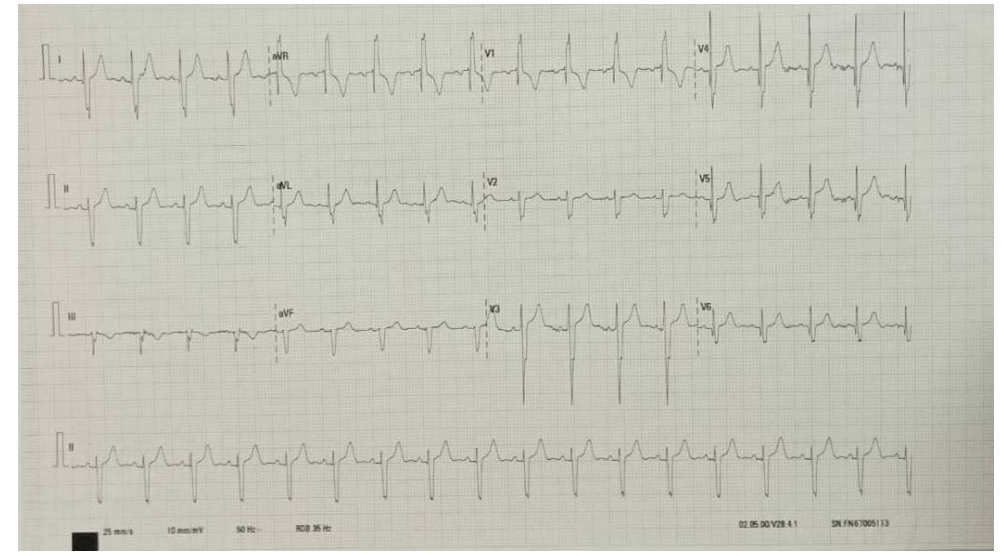

Figure 4. Sinus rhythm 3 days after operation.

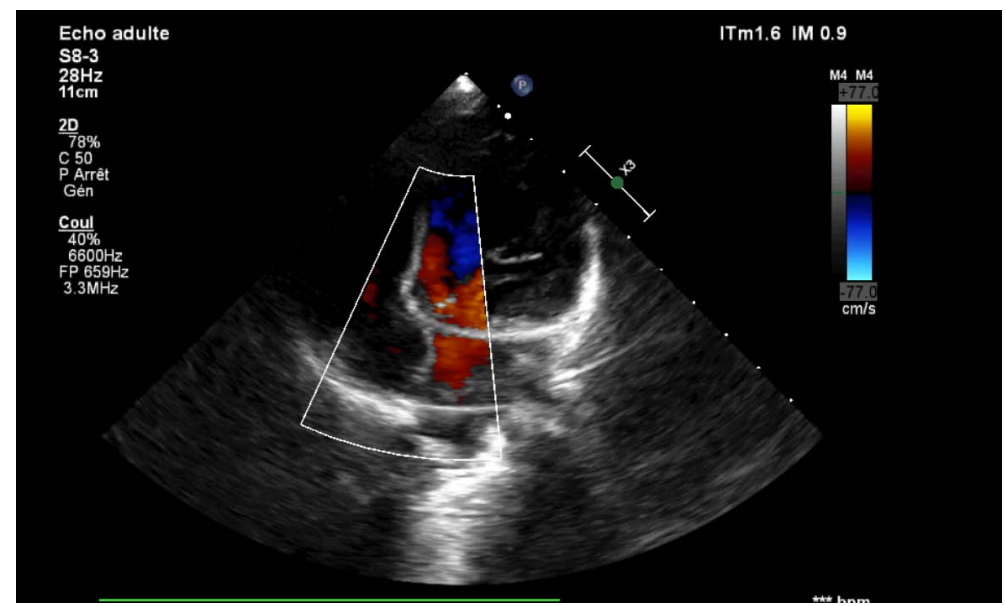

Figure 5. Doppler echocardiography at 6-month after correction objectified a VSD patch in place. 


\section{Discussion}

Atrioventricular septal defect is a rare congenital heart disease (4\% - 7\%) [1] [3]. It can present itself in a form without an atrial septal defect (ASD). It is a variant that can be encountered and classified in the intermediate form by some authors [3]. In these cases, there is a deficiency of the atrioventricular junction, but the tissue of the atrioventricular valves is attached to the atrial edge of the defect. It results is an absence of shunting at the atrial level [6].

Despite the absence of a genetic diagnosis, which is not accessible, our patient have a Down syndrome morphology. Atrioventricular septal defect is the most common congenital heart disease in this field [2].

This form is like atrioventricular septal defect with a large inlet ventricular septal defect which is early symptomatic [7]. Its particularity is the absence of shunting at the atrial level (ostium primum atrial septal defect) associated with a large $17 \mathrm{~mm}$ inlet VSD, a single atrioventricular valve (AVV). In the literature, interventricular shunting alone (inlet ventricular septal defect), or both (most complete Atrioventricular septal defect) can exist depending on whether or not the bridging leaflets are attached to the septal structures [3]. Therefore an author has described a case of atrioventricular septal defect with intact septal structures [8]. Symptoms a failure to gain weight, dyspnea, hyperactive precordium, and a wide ejection systolic murmur area at the left sternal border due to the left to right shunt that resulted in an early rise in lung pressure [1] [9]. The EKG signs (RAH, RVH) observed in our case, are also arguments in favor of diagnosis [3] [10].

The presence of a left upper vena cava vein draining into a dilated coronary sinus (CS) can simulate an atrial septal defect (ASD) at the echocardiography. To have a better understanding of this type of atrioventricular septal defect, the surgeon has to open the interatrial septum in the foramen ovale to allow a better approach and repair of the left component.

Early after the intervention, the occurrence of a junctional rhythm could be explained by an edema of the nodal triangle which is not the same in complete AVSD [11]. It is corroborated by the return to sinus rhythm after 10-days corticotherapy. Infection is common in this area, in our case the diagnosis was retained on the appearance of secretions at extubation. The occurrence of pericardial effusion is also noted more often in cases of Down syndrome.

The long-term prognosis depends on the evolution of a residual mitral regurgitation [12] [13]. It may be favorable because repair in this area of Down syndrome is more favorable [3] [5]. Also, the rise of systolic pulmonary blood pressure has to be taken into account. In our case, the patient was put on pulmonary vasodilator (sildenafil). The residual VSD is mild and will only need to be monitored.

\section{Conclusion}

Atrioventricular septal defect without atrial septal defect is a rare congenital 
heart disease. Often symptomatic, it can be revealed by early signs of heart failure. Its diagnosis is facilitated by the Doppler echocardiography which is the gold standard examination. The contribution of catheterization is to be emphasized because of the frequent coexistence of signs of pulmonary arterial hypertension. To avoid its fatal prognosis, early surgical correction is often necessary when symptomatic or if the shunt is not restrictive.

\section{Financial Support}

No extramural funding was obtained for this work.

\section{Disclosures}

No disclosure.

\section{Conflicts of Interest}

The authors declare no conflicts of interest regarding the publication of this paper.

\section{References}

[1] Calkoen, E.E., Hazekamp, M.G., Blom, N.A., Elders, B.B.L.J., de Groot, A.C.G., Haak, M.C., Bartelings, M.M., Roest, A.A.W. and Jongbloed, M.R.M. (2016) Atrioventricular Septal Defect: From Embryonic Development to Long-Term Follow-Up. International Journal of Cardiology, 202, 784-795. https://doi.org/10.1016/j.ijcard.2015.09.081

[2] Versacci, P., Di Carlo, D., Digilio, M.C. and Marino, B. (2018) Cardiovascular Disease in Down Syndrome. Current Opinion in Pediatrics, 30, 616-622. https://doi.org/10.1097/MOP.0000000000000661

[3] Becker, A.E. and Anderson, R.H. (1982) Atrioventricular Septal Defects: What's in a Name? Journal of Thoracic and Cardiovascular Surgery, 83, 461-469. https://doi.org/10.1016/S0022-5223(19)37286-1

[4] Gutgesell, H.P. and Huhta, J.C. (1986) Cardiac Septation in Atrioventricular Canal Defect. Journal of the American College of Cardiology, 8, 1447-1450. https://doi.org/10.1016/S0735-1097(86)80317-5

[5] Falcão, S., Daliento, L., Ho, S.Y., Rigby, M.L. and Anderson, R.H. (1999) Cross Sectional Echocardiographic Assessment of the Extent of the Atrial Septum Relative to the Atrioventricular Junction in Atrioventricular Septal Defect. Heart, 81, 199-205. https://doi.org/10.1136/hrt.81.2.199

[6] Barratt-Boyes, K. (2013) Atrioventricular Septal Defect in Cardiac Surgery. Fourth Edition, Elsevier Saunders, Amsterdam, 1227-1273.

[7] Smallhorn, J.F., Sutherland, G.R., Anderson, R.H. and Macartney, F.J. (1982) Cross-Sectional Echocardiographic Assessment of Conditions with Atrioventricular Valve Leaflets Attached to the Atrial Septum at the Same Level. British Heart Journal, 48, 33141. https://doi.org/10.1136/hrt.48.4.331

[8] Ho, S.Y., Russell, G. and GerIis, L.M. (1990) Atrioventricular Septal Defect with Intact Septal Structures in a 74-Year-Old. International Journal of Cardilogy, 26, 371-373. https://doi.org/10.1016/0167-5273(90)90097-O

[9] Kaski, J.P., Wolfenden, J., Josen, M., Daubeney, P.E.F. and Shinebourne, E.A. (2006) 
Can Atrioventricular Septal Defects Exist with Intact Septal Structures? Heart, 92, 832-835. https://doi.org/10.1136/hrt.2005.069278

[10] Haddad, A., et al. (2015) Chirurgie des cardiopathies congénitales à l'âge adulte. A propos de 540 cas. Annales de cardiologie et d angiologie, 64, 41-248. https://doi.org/10.1016/j.ancard.2015.02.005

[11] Anderson, R.H., Ho, S.Y. and Becker, A.E. (1983) The Surgical Anatomy of the Conduction Tissues. Thorax, 38, 408-420. https://doi.org/10.1136/thx.38.6.408

[12] Sarısoy, Ö., Ayabakan, C., Tokel, K., Özkan, M., Türköz, R. and Aşlamac, S. (2018) Long-Term Outcomes in Patients Who Underwent Surgical Correction for Atrioventricular Septal Defect. Anatolian Journal of Cardiology, 20, 229-234. https://doi.org/10.14744/AnatolJCardiol.2018.39660

[13] Geoffrion, T.R., Singappuli, K. and Murala, J.S.K. (2018) A Review of the Nunn Modified Single Patch Technique for Atrioventricular Septal Defect Repair. Translational Pediatrics, 7, 91-103. https://doi.org/10.21037/tp.2018.02.05 